\title{
The impact of RFID on management of returnable containers
}

\author{
Lars Thoroe • Adam Melski • Matthias Schumann
}

Received: 7 December 2008 / Accepted: 2 June 2009 / Published online: 10 July 2009

C) The Author(s) 2009. This article is published with open access at Springerlink.com

\begin{abstract}
Inventory shrinkage is a common problem in the management of returnable containers. RFID-based container tracking systems have been proposed as a possible solution. Benefits of RFID-based tracking of returnable transport items such as pallets, kegs and boxes are documented in several case studies, but have so far hardly been analyzed from a theoretical perspective. In this article, we analyze the impact of RFID on container management using a deterministic inventory model. The analysis focuses firstly on inventory control for which we deduce changes due to RFID for the optimum policy. We then turn to the profitability of the RFID system and determine relevant relations of costs and benefits. Finally we analyze alternatives of implementing an RFID-based container tracking system. These alternatives are analyzed with respect to diffusion speed and profitability.
\end{abstract}

Keywords RFID - Returnable containers .

Reusable transport items $\cdot$ Reverse logistics

JEL L91

\section{Introduction}

Successful applications of RFID technology in logistics systems are still relatively scarce. Item-level tagging will

Responsible editor: Frédéric Thiesse

L. Thoroe $(\bowtie) \cdot$ A. Melski $\cdot$ M. Schumann

Institut für Wirtschaftsinformatik,

Georg-August-Universität Göttingen,

Platz der Göttinger Sieben 5,

37073 Göttingen, Germany

e-mail: 1thoroe@uni-goettingen.de hardly be profitable in the medium-term considering most scenarios, most of the successful pilot projects can be found in closed-loop scenarios which allow for a reuse of transponders. A promising area for potential RFID systems is tracking of reusable containers, such as pallets, bins, kegs, etc.: In this application area, benefits of RFID have been documented in case studies (e.g. Johansson and Hellström 2007; Strassner and Fleisch 2005) and the interest of practice has been confirmed in empirical studies (Breen 2006; Hofmann and Bachmann 2006). However, previous research has so far focused on case studies of isolated projects, theoretical analysis of the benefits of RFID in this area, which covers general effects and interdependencies, is lacking.

Closed-loop logistics systems are the subject of an area of logistics research which has been gaining in importance since the mid-1990s and is denoted as reverse logistics. This area deals with flows of material which run in the opposite direction of the classical supply chain and their reintegration into the supply chain. Reverse logistics research has provided a number of inventory models which incorporate returning material flows. This research serves as a basis for our analysis of the impact of RFID on the management of returnable containers.

The article is organised as follows: In the following section, we present a brief overview of the use of RFID systems in container management as well as related work. We then present the model which our analysis is based on. The subsequent analysis of the impact of RFID addresses three aspects: First, we analyze the effects of the RFID implementation on optimum inventory control policy. We then assess the profitability of a RFID-based container tracking system. Finally, we discuss and assess implementation alternatives with respect to speed of diffusion and profitability. 


\section{Background and related work}

RFID in container management

In recent years, several articles have dealt with the management of returnable containers and the challenges associated with this task. The term returnable container as used in this article (in accordance with Kroon and Vrijens 1995 and Witt 2000) refers to all kinds of returnable packaging material which is used in transport processes, such as pallets, bins, roll containers, kegs or stillages. Synonyms for the term are returnable transport items (Johansson and Hellström 2007) and reusable packaging items (McKerrow 1996).

Container management is resource-intensive: In a survey by Aberdeen Group (2004) almost half of the respondents reported that the cost of managing logistics assets consumes $5 \%$ or more of corporate revenue. A major issue in this area is the problem of shrinkage due to theft, undocumented damage or simply the failure of customers to return empty containers (Breen 2006; Witt 2000; McKerrow 1996; LogicaCMG 2004); McKerrow (1996) reports "numerous examples of equipment pools [...], where the entire pool has been lost within only a few months". The cases reported by Breen (2006) are less drastic, however, her study over multiple industry sectors in the UK shows, that loss of returnable containers is a serious issue: "A palletpooling agent $[\ldots]$ stated that $15 \%$ of pallets in circulation disappear". Another logistics company estimated that " $20 \%$ of all packaging/equipment being lost due to customers retaining them for own use or third parties removing them for their use" (Breen 2006).

One way to tackle these problems is the implementation of some kind of tracking system based on identification technology. Barcode labels which are used to tag the load of a container during shipment are mostly non-permanent; they identify the contents rather than the containers themselves and can therefore hardly be used in reverse logistics processes of the container. Using permanent barcode labels as the basis for a container tracking system is in many cases not a viable solution: Scanning the labels at different points of the supply loop often requires too much manual labour and is even more difficult when empty containers are stacked (Vitzthum and Konsynski 2008). Because of the advantages of RFID (fully automatable reading without line-of-sight, bulk reading) this technology is appealing for companies which face to abovementioned problems in container management: In a study by Hofmann and Bachmann (2006) the respondents reported a high interest in potential benefits of RFID in order to reduce shrinkage, although very few had actually implemented an RFID-based container tracking system. However, successful implementations of these systems are well documented in several case studies. Table 1 shows an overview of case studies from different industries.

\section{Analyzing benefits of RFID using inventory models}

Inventory models are an established instrument for analyzing the business impacts of RFID. Several authors have used inventory models (mostly based on existing models taken from OR literature) as the basis for their analysis of benefits of RFID systems: Kang and Gershwin (2005); Lee and Özer (2007) and Heese (2007) use inventory models to analyze the impact of RFID to tackle inventory record inaccuracy in retail scenarios. De Kok et al. (2008) conduct a cost-benefit analysis of the implementation of RFID for theft prevention in retail using inventory models. Saygin (2007) analyzes benfits of RFID data in a shop floor manufacturing environment. All these works address the impacts of RFID either on isolated inventory systems (e.g. retail store) or on classical multiechelon supply chains with unidirectional material flows.

Table 1 Case studies of RFID implementations in container management

\begin{tabular}{|c|c|c|c|}
\hline Industry & Container type & Benefits & Reference \\
\hline Automotive & $\begin{array}{l}\text { Containers for automobile } \\
\text { parts }\end{array}$ & Reduced shrinkage accelerated search processes & $\begin{array}{l}\text { Strassner and Fleisch } \\
2005\end{array}$ \\
\hline Automotive & $\begin{array}{l}\text { Stillages for automobile } \\
\text { parts }\end{array}$ & Reduced shrinkage and misplacement of stillages & Foster et al. 2006 \\
\hline $\begin{array}{l}\text { Fast moving consumer } \\
\text { goods }\end{array}$ & Roll containers & Reduced shrinkage & $\begin{array}{l}\text { Johansson and } \\
\text { Hellström } 2007\end{array}$ \\
\hline $\begin{array}{l}\text { Fast moving consumer } \\
\text { goods }\end{array}$ & Vegetable crates & Reduced shrinkage, accelerated search processes & $\begin{array}{l}\text { Sectoral e-Business } \\
\text { Watch } 2008\end{array}$ \\
\hline Beverages & Beer kegs & Reduced shrinkage & $\begin{array}{l}\text { Lampe and Strassner } \\
2003\end{array}$ \\
\hline $\begin{array}{l}\text { Container pool service } \\
\text { provider }\end{array}$ & Crates & $\begin{array}{l}\text { Cost savings from claims, deposits, reconciliation with } \\
\text { retailers and growers }\end{array}$ & $\begin{array}{l}\text { Sectoral e-Business } \\
\text { Watch } 2008\end{array}$ \\
\hline $\begin{array}{l}\text { Container pool service } \\
\text { provider }\end{array}$ & $\begin{array}{l}\text { Wooden pallets and plastic } \\
\text { containers }\end{array}$ & Reduced loss and increased availability of pallets & $\begin{array}{l}\text { Vitzthum and } \\
\text { Konsynski } 2008\end{array}$ \\
\hline
\end{tabular}


Container management, however, deals with forward flows as well as return flows, which form a closed-loop system. Inventory control in closed-loop systems with interrelated forward and reverse flows is the subject of reverse logistics.

Reverse logistics inventory models

This article is based on a deterministic inventory model, i.e. decision relevant variables are assumed to be known and static. The main subject of inventory models is lot sizing, i.e. the decision problem of finding the optimum production or procurement batch size. The first deterministic inventory model for determining optimum procurement lot sizes is the so called classical EOQ (economic order quantity) model, dating back to Harris (1913) and Wilson (1934). This static model has been extended by many authors in order to incorporate reverse material flows (for a comprehensive review see Fleischmann et al. 1997). One of the first articles in this context describes an inventory model for repairable items (Schrady 1967). The optimum policies for procurement and refurbishment developed in this work have been the basis for many future works since the area of reverse logistics has evolved into an important field of research in the mid1990s (e.g. Richter 1996a, b; Teunter 2001; Minner and Lindner 2004). The model used in this article is based on the general reverse logistics model presented by Minner and Lindner (2004) and is adapted in order to analyze the impact of RFID on container logistics systems (cf. Minner and Lindner 2004 and Schrady 1967 for the basic model).

Our analysis is divided into three parts: In the first part we focus on inventory control. We slightly adapt the basic model presented by Schrady (1967) and Minner and Lindner (2004) and analyze the changes on the optimum inventory control policy induced by the implementation of an RFIDbased container tracking system. For the subsequent analysis, the basic model (which was designed for analyzing lot sizing decisions) is no longer sufficient. We extend the model by including additional variable costs and conduct an analysis of profitability of an RFID-based container tracking system in the second part. The third part of our analysis focuses on implementation alternatives for the RFID system, which we analyze and compare with regards to diffusion speed and profitability.

\section{Model definition and initial situation}

We consider a company which uses one kind of returnable containers in the distribution of their products (see Fig. 1). We assume constant and deterministic amounts of containers delivered to (b) and returned from customers (u) per unit of time $(\mathrm{t})$. We further assume $\mathrm{u}<\mathrm{b}$, which means that the demand cannot be satisfied completely with returning

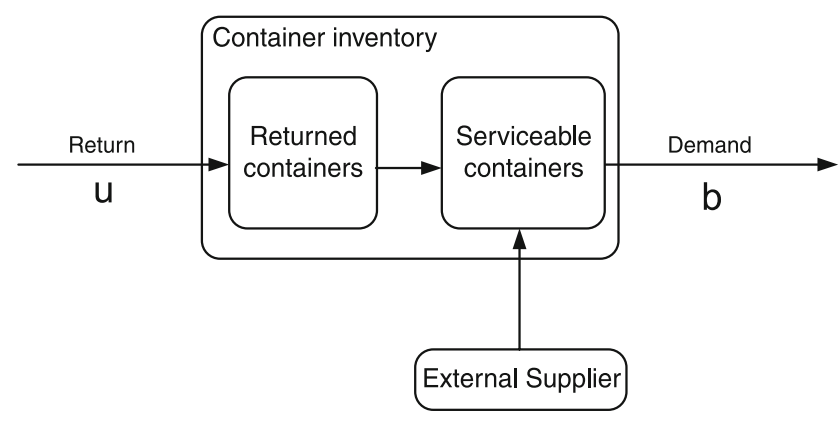

Fig. 1 Basic container inventory system

containers and new containers have to be procured from an external supplier.

Two inventories are considered: returned containers and serviceable containers. The majority of empty containers returning from customers can be refurbished and reused for future deliveries. Returning containers which are worn-out and not worth refurbishing and containers which fail to be returned are counted as shrinkage. Average shrinkage per period is $b-u$. Containers worth the effort of refurbishment are assumed to be of equal quality and are refurbished into serviceables. In the simplest case, refurbishment of a container merely consists of inspection in order to ensure its utilisability. In other cases, refurbishment may require cleaning (e.g. in order to comply with hygiene requirements if the containers are used for the distribution of food products) or repair and maintenance processes. The inventory of serviceable containers consists of refurbished containers as well as new containers, which are procured in order to compensate for shrinkage. Lead times for refurbishment and procurement are disregarded. Demand for containers is satisfied instantaneously, backorders are not permitted.

The following notation is used throughout the article:

b : demand rate (containers delivered in $\mathrm{t}$ )

$\mathrm{u}$ : return rate (empty containers returned in $\mathrm{t}$, excluding damaged containers beyond repair)

$\mathrm{K}_{\mathrm{p}}$ : fixed ordering cost

$\mathrm{K}_{\mathrm{r}}$ : refurbishment setup cost

$\mathrm{Q}_{\mathrm{p}}$ : procurement lot size

$\mathrm{Q}_{\mathrm{r}}$ : refurbishment lot size

$\mathrm{k}_{\mathrm{p}} \quad$ : container price

$\mathrm{k}_{\mathrm{r}}$ : variable refurbishment cost per container

w : holding cost rate for containers in per cent per unit of time

The following cost functions are considered: The sum of setup costs for procurement (fixed ordering costs) and refurbishment and holding costs per unit of time is given by

$C f=\frac{K_{p}(b-u)}{Q_{p}}+\frac{K_{r} u}{Q_{r}}+\frac{w k_{p}}{2} Q_{p}+w k_{p} \frac{u}{b} Q_{r}$ 
The cost function above is similar to the total relevant costs in the model of Minner and Lindner (2004). There are however some differences: Minner and Lindner set the holding costs as a parameter per unit and unit of time, whereas in our model, the product of the container price and a holding cost rate in per cent per unit of time is used. This is due to the fact that Minner and Lindner do not explicitly consider variable costs for procurement (for the reasons given below), whereas for our analysis these variable costs are essential. Furthermore, Minner and Lindner use different holding costs for returned and serviceable products, as they consider repairable items in general and therefore account for the possibly significant differences regarding the value of returned products and servicables. We assume these differences in value to be lower in the specific case of returnable containers and therefore use the same holding costs for both inventories (note that the inventory of returned containers does not include containers damaged beyond repair, as mentioned above). Finally, Minner and Lindner do not consider variable costs, as they focus on lot sizing decisions (i.e. inventory control policy), which are independent from variable cost of procurement and refurbishment, if no disposal option is included. In contrast to this, we do consider the variable costs for procurement and refurbishment of containers:

$C v=(b-u) k_{p}+u k_{r}$

The sum of these two functions yields the total relevant costs:

$T C=C f+C v$

Assuming constant batch sizes for refurbishment and procurement, two opposite control policies have to be considered (Minner and Lindner 2004; Schrady 1967; Teunter 2001):

- A single procurement batch is followed by $\mathrm{R}$ refurbishment batches (1:R policy)

- A single refurbishment batch is followed by $\mathrm{P}$ procurement batches ( $\mathrm{P}: 1$ policy)
Teunter (2001) proves that other possible policies do not have to be considered as they are dominated by one of the above policies. Minner and Lindner (2004) show that the 1:R policy is preferable for systems with a high return ratio $(\mathrm{u} /$ $\mathrm{b} \rightarrow 1)$ and the P:1 policy is preferable in the opposite case $(\mathrm{u} / \mathrm{b} \rightarrow 0)$. In comparison to general reverse logistics systems, management of returnable containers can be assumed to usually operate with rather high return ratios, hence we focus on the 1:R policy in our analysis (see Fig. 2).

Evaluating the first order conditions of (1) yields the following parameters of the optimum inventory control policy. The optimum lot sizes for procurement and refurbishment are

$Q_{p}^{*}=\sqrt{\frac{2(b-u) K_{p}}{w k_{p}}}$

and

$Q_{r}^{*}=\sqrt{\frac{b K_{r}}{w k_{p}}}$.

The optimum number of consecutive refurbishment batches is:

$R^{*}=\frac{\frac{u}{b}}{1-\frac{u}{b}} \frac{Q_{p}^{*}}{Q_{r}^{*}}=\frac{\frac{u}{b}}{1-\frac{u}{b}} \sqrt{\frac{2 K_{p}}{K_{r}\left(\frac{1}{1-\frac{u}{b}}\right)}}$.

Inserting (4) and (5) in (1) yields the minimum of the costs relevant for inventory control policy:

$C f^{*}=2 u \sqrt{\frac{w k_{p} K_{r}}{b}}+\sqrt{2(b-u) w k_{p} K_{p}}$

\section{Impact of RFID-based container tracking}

We now analyze the impact of the implementation of a RFID-based tracking system on the inventory system. The following section deals with effects (i.e. costs and benefits)
Fig. 2 Impact of RFID on inventory of serviceable containers
Inventory of serviceable containers

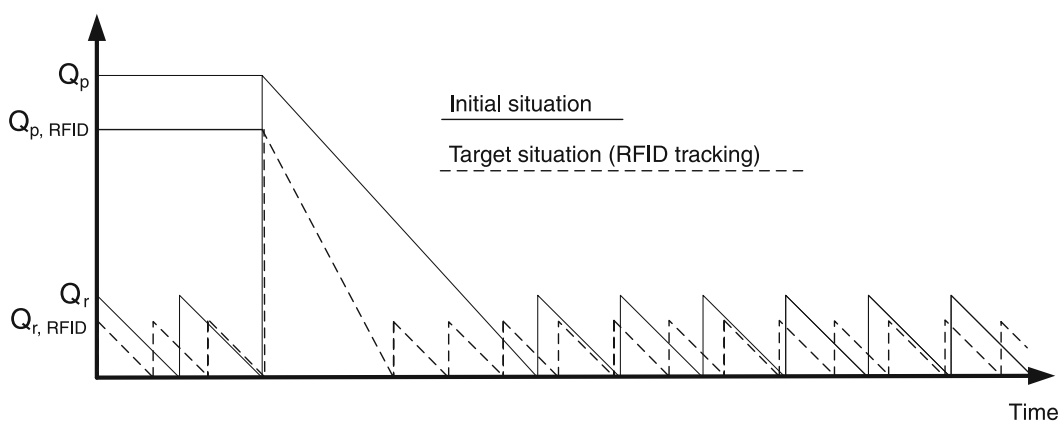


of the RFID system on model variables. We then analyze the impact on optimum inventory control policy. Afterwards, we focus on the profitability of the tracking system.

Costs and benefits

According to the practical experiences with RFID-based container tracking systems, we consider an increase of the return rate $\Delta \mathrm{u}$ to be the main benefit. We do not include other benefits (e.g. a reduction of variable refurbishment costs). As costs of the RFID system we analyze an increase of the container price $\Delta \mathrm{k}_{\mathrm{p}}$ due to tagging. For the sake of clarity of the model, we do not incorporate further costs, such as write-offs for reader infrastructure, software and integration as well as running costs, which could be introduced by adding further terms as costs per unit or time.

The impact of the implementation of the RFID system is analyzed on the basis of two situations: In the initial situation $\left(\mathrm{k}_{\mathrm{p}, 0}, \mathrm{u}_{0}\right)$, no container is equipped with a transponder. In the target situation a fraction of the container inventory is tagged, which is high enough to achieve the increase of the container return rate. The target situation is determined by $\left(k_{\mathrm{p}, \text { RFID }}, \mathrm{u}_{\mathrm{RFID}}\right)$. The focus of this section is on the comparison of these two situations. The time between initial and target situation, i.e. the diffusion of RFID in the model, will be dealt with at the end of the article.

Inventory control policy

We now analyze the effects of $\Delta \mathrm{u}=\mathrm{u}_{\mathrm{RFID}}-\mathrm{u}_{0}$ and $\Delta \mathrm{k}_{\mathrm{p}}=$ $\mathrm{k}_{\mathrm{p}, \mathrm{RFID}}-\mathrm{k}_{\mathrm{p}, 0}$ on the optimum inventory control policy.

\section{Optimum procurement lot size}

Partial differentiation of (4) with respect to $u$ and $k_{p}$ yields

$\frac{\partial Q_{p}^{*}}{\partial u}=-\sqrt{\frac{K_{p}}{2(b-u) w k_{p}}}<0$

and

$\frac{\partial Q_{p}^{*}}{\partial k_{p}}=-\frac{1}{k_{p}^{2}} \sqrt{\frac{K_{p}(b-u) k_{p}}{2 w}}<0$.

Hence, $\mathrm{Q}^{*}{ }_{\mathrm{p}}\left(\mathrm{u}, \mathrm{k}_{\mathrm{p}}\right)$ is monotonically decreasing on the interval considered:

$Q_{p}^{*}\left(u_{R F I D}, k_{p, R F I D}\right)<Q_{p}^{*}\left(u_{0}, k_{p, 0}\right)$.

The relative change of the optimum procurement lot size is:

$\frac{Q_{p}^{*}\left(u_{R F I D}, k_{p, R F I D}\right)}{Q_{p}^{*}\left(u_{0}, k_{p, 0}\right)}-1=\sqrt{\frac{k_{p, 0}}{k_{p, R F I D}}} \sqrt{\frac{b-u_{R F I D}}{b-u}}-1$.

\section{Optimum refurbishment lot size}

The optimum refurbishment batch size is also decreasing after the RFID implementation, as more capital is tied up in the inventory:

$$
\begin{aligned}
\frac{\partial Q_{r}^{*}}{\partial k_{p}} & =-\frac{1}{2 k_{p}^{2}} \sqrt{\frac{b k_{p} K_{r}}{w}}<0 \Rightarrow Q_{r}^{*}\left(k_{p, R F I D}\right) \\
& <Q_{r}^{*}\left(k_{p, 0}\right)
\end{aligned}
$$

The relative change of the optimum refurbishment lot size is:

$$
\frac{Q_{r}^{*}\left(k_{p, R F I D}\right)}{Q_{r}^{*}\left(k_{p, 0}\right)}-1=\sqrt{\frac{k_{p, R F I D}}{k_{p, 0}}}-1 .
$$

\section{Optimum number of consecutive refurbishment batches}

The last parameter of the inventory control policy is $\mathrm{R}^{*}$. Because of

$$
\begin{aligned}
\frac{\partial R^{*}}{\partial u}= & \frac{1}{b} \sqrt{\frac{2 K_{p}}{K_{r}\left(1-\frac{u}{b}\right)}}+\frac{u}{b^{2}\left(1-\frac{u}{b}\right)^{2}} \sqrt{\frac{K_{p}\left(1-\frac{u}{b}\right)}{2 K_{r}}} \\
& >0 \quad \forall u \in] 0, d[
\end{aligned}
$$

$\mathrm{R}^{*}(\mathrm{u})$ is monotonically increasing on the relevant interval, i.e.

$\left.R^{*}\left(u_{R F I D}\right)>R^{*}\left(u_{0}\right) \forall u \in\right] 0, d[$

The relative change of the optimum number of consecutive refurbishment batches is:

$\frac{R^{*}\left(u_{R F I D}\right)}{R^{*}\left(u_{0}\right)}-1=\sqrt{\frac{u_{R F I D}}{u}} \sqrt{\frac{1-\frac{u}{b}}{1-\frac{u_{R F I D}}{b}}}-1$

The impact of implementing the RFID-based tracking system on the optimum inventory control policy is summarized in Table 2:

These changes are illustrated in Fig. 2, which depicts the development of the inventory of serviceable containers:

\section{Profitability}

The total costs of the system per unit of time consist of two components, firstly, the optimum setup costs and holding costs (7) (we assume that the optimum control policy is applied), and secondly, the variable costs for procurement and refurbishment (2). To illustrate the composition of the total costs, we now examine a numerical example: We consider a company which uses 500 containers per day for shipments to customers. In accordance with analyzed case studies (see Table 1) we assume that daily returns are in the range of 250 to 500 containers. Regarding the price, we 
Table 2 Impact of RFID on inventory control policy

\begin{tabular}{|c|c|c|c|}
\hline \multirow[t]{2}{*}{ Variable } & \multicolumn{3}{|l|}{ Impact } \\
\hline & Cause & Direction & Relative change \\
\hline Optimum procurement lot size $Q_{p}^{*}$ & $u_{R F I D}, k_{p, R F I D}$ & Reduction & $\sqrt{\frac{k_{p, 0}}{k_{p, R F I D}}} \sqrt{\frac{b-u_{R F I D}}{b-u_{0}}}-1$ \\
\hline Optimum refurbishment lot size $Q_{r}^{*}$ & $k_{p, R F I D}$ & Reduction & $\sqrt{\frac{k_{p, R F I D}}{k_{p, 0}}}-1$ \\
\hline Optimum number of consecutive refurbishment batches $R^{*}$ & $u_{R F I D}$ & Increase & $\sqrt{\frac{u_{R F I D}}{u_{0}}} \sqrt{\frac{1-\frac{u_{0}}{b}}{1-\frac{u_{R F I D}}{b}}-1}$ \\
\hline
\end{tabular}

examine a wide spectrum of containers, starting from simple wooden pallets for $5 €$ up to more costly types of special containers for $200 €$. For the sake of simplicity, we keep the variable cost for refurbishment constant at $5 €$. We base the holding cost rates on a calculatory interest rate of approx. $5 \%$ p.a. (or $0.1 \%$ per day). The composition of the total costs of this scenario is shown in Fig. 3. The cost functions are plotted against the relevant variables $u$ and $k_{p}$.

In the numerical example, the total costs are almost completely determined by the variable costs for procurement and refurbishment. For the sake of argumentation, we chose rather high values for the refurbishment setup costs and fixed ordering costs (500€ and $1000 €)$. Even so, setup costs and holding costs, which determine the optimum control policy, are negligible. This becomes apparent for the general case as well when the ratio of the two components is considered:

$\frac{C f^{*}}{C v}=\frac{2 u \sqrt{\frac{w k_{p} K_{r}}{b}}+\sqrt{2(b-u) w k_{p} K_{p}}}{u k_{r}+(b-u) k_{p}}$

Hence we use the variable costs as an approximation for the total cost in the analysis of the profitability of the RFID system:

$$
C v(u, r)=(b-u) k_{p}+u k_{r}
$$

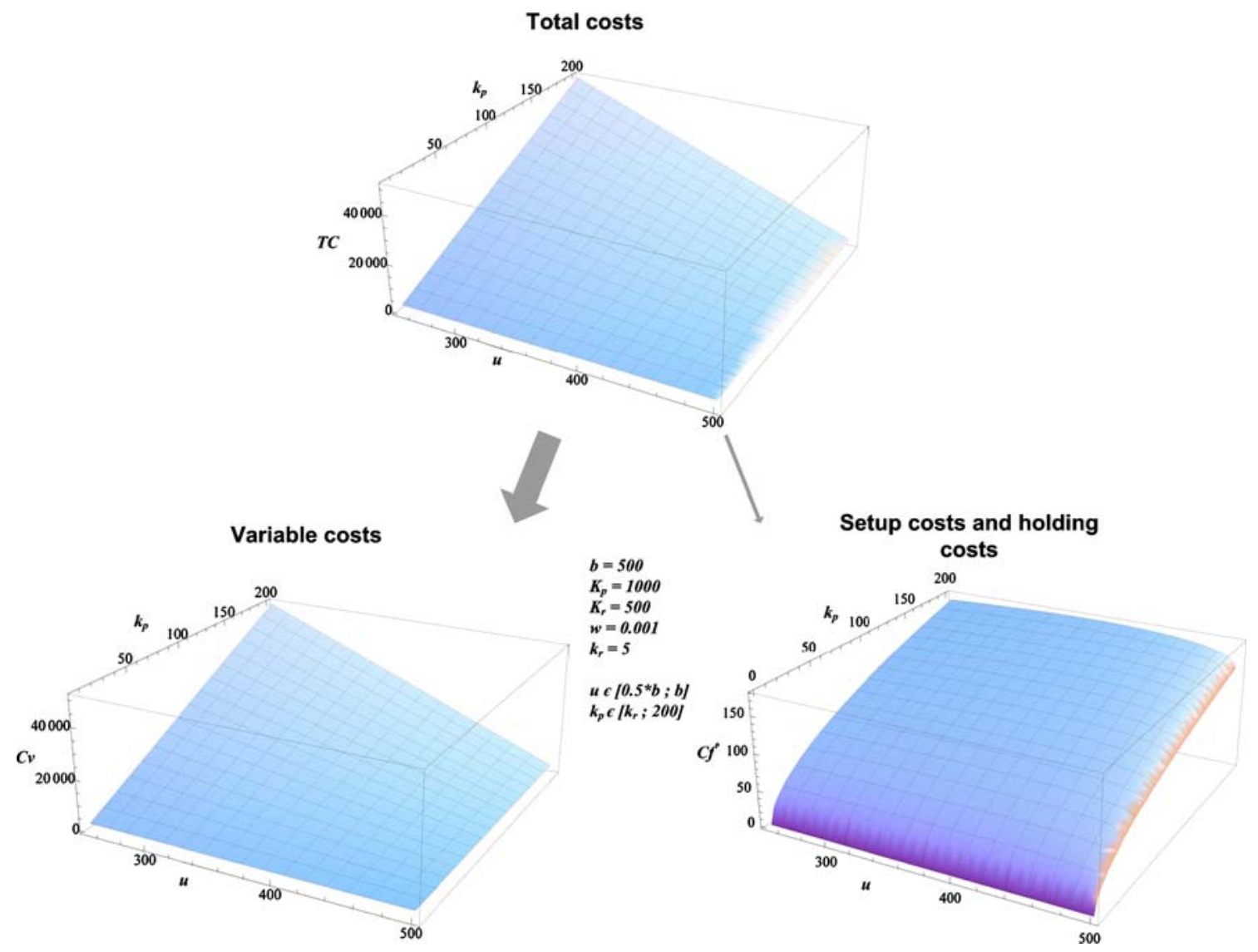

Fig. 3 Exemplary composition of total costs 
The example above shows that an increase of $u$ c.p. reduces the variable costs, but the increase of $k_{p}$ c.p. increases the costs. The general partial differentiations are:

$\frac{\partial C v}{\partial u}=k_{r}-k_{p}<0$

and

$\frac{\partial C v}{\partial k_{p}}=b-u>0$

These opposite isolated impacts now have to be analyzed for their simultaneous behaviour. Hence we consider the changes of relevant costs:

$$
\begin{aligned}
\Delta R C=C v_{R F I D}-C v_{0}= & \left(b-u_{0}\right) \Delta k_{p} \\
& +\left(k_{r}-k_{p, 0}\right) \Delta u-\Delta k_{p} \Delta u
\end{aligned}
$$

The implementation of the RFID system leads to an overall cost reduction, if

$\Delta R C<0 \Leftrightarrow \frac{b-u_{0}}{\Delta u}-\frac{k_{p, 0}-k_{r}}{\Delta k_{p}}<1$

For a given initial situation, inequation (22) describes the relationship between costs and benefits, which is necessary for a profitable use of the RFID system. Transforming this inequation yields the minimum benefit, which has to be reached for a successful use of the system for given costs of tagging.

$\Delta u>\frac{\Delta k_{p}}{k_{p, R F I D}-k_{r}}\left(b-u_{0}\right)$

Inversely, for a given benefit of RFID, the upper bound of tagging costs in order to ensure profitability is given by:

$\Delta k_{p}<\frac{\Delta u}{b-u_{R F I D}}\left(k_{p, 0}-k_{r}\right)$

\section{Diffusion}

In the following we analyze the diffusion speed of RFID in the system considered in order to determine the time between base and target scenario compared in the last chapters. The question we focus on here is essential for object design changes in reverse logistics contexts:
Reverse logistics may deal with objects years after their initial production, therefore unchanged objects have to be handled for a significant time after the first implementation of object-related changes. The increase of the return rate will not occur instantaneously once the first RFIDequipped containers have been purchased. Thus, the question is: Starting from the first procurement of containers tagged with RFID, how long does it take until a fraction of the container inventory is tagged, which is high enough to yield the described benefits? This necessary fraction is denoted as $\alpha$ (Fig. 4).

\section{Implementation alternatives}

For the following analysis we extend the inventory considered. So far, we have focused solely on those containers in the current possession of the company; we now consider the inventory of the complete system which also encompasses the company's clients. This complete inventory of containers (B) is assumed to be constant. Lot sizes for procurement and refurbishment are not of relevance here and we assume that in each period a constant amount of new containers is procured and refurbished respectively. Shrinkage in $t$ is replenished with newly procured containers instantaneously. For the time of diffusion we assume the constant return rate:

$\bar{u}=\frac{u_{0}+u_{R F I D}}{2}$

Two opposite alternatives regarding the implementation of RFID are possible: Either only newly procured containers are tagged with transponders (alternative 1) or, additionally, the existing container inventory is equipped with RFID tags during refurbishment (alternative 2, see Fig. 5).

Subject of the analysis is now the fraction of tagged containers relative to the complete container inventory B:

$a_{i t}$ : fraction of tagged containers in relation to $B$ in period $t$ when using alternative $i$

\section{Alternative 1: Replenishment of tagged containers}

In this case, only newly procured containers are tagged. In each period (b-û) tagged containers enter the system and
Fig. 4 Time lag between the compared situations
Initial situation:

fraction of tagged containers $=0$
Target situation:

fraction of tagged containers $>\alpha$

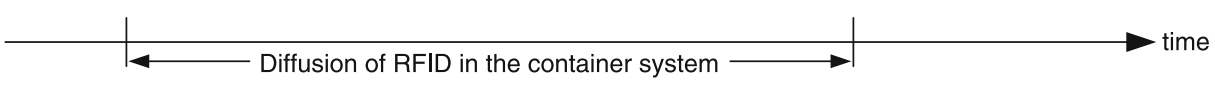




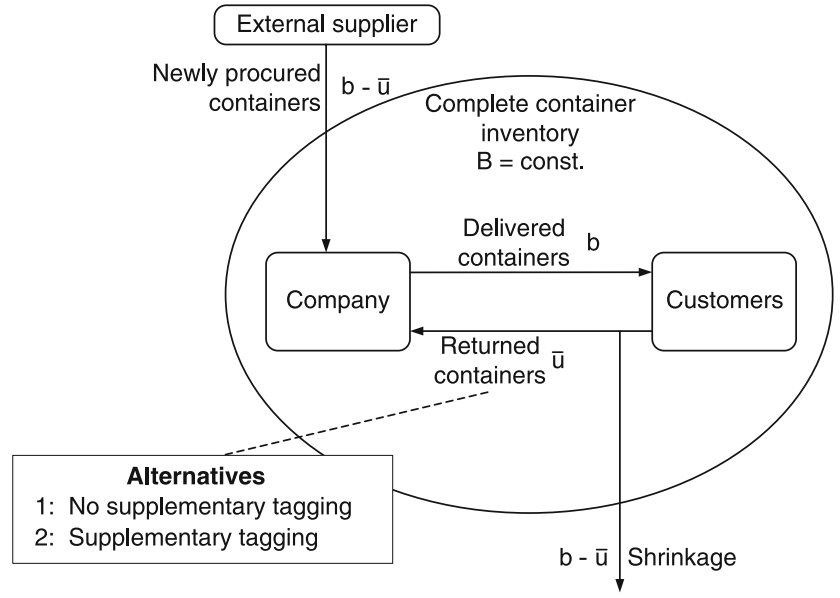

Fig. 5 Inventory system and implementation alternatives

$a_{1 t}(b-\hat{u})$ tagged containers leave the system due to shrinkage. Thus, the fraction of tagged containers in $t$ is defined by the following recurrence relation:

$a_{1 t}= \begin{cases}0 & \text { if } t=0 \\ a_{1 t-1}+\frac{(b-\bar{u})\left(1-a_{1 t-1}\right)}{B} & \text { else }\end{cases}$

We now determine $t_{1 \alpha}$, so that

$a_{1 t a} \geq \alpha$.

For this purpose, it is useful to transform the sequence into its closed-form expression, which is given by

$a_{1 t}=1-\left(1-\frac{b-u}{B}\right)^{t}$

The proof of this statement is done by induction. For the sake of clarity $a_{1 t}$ is referred to simply as $a_{t}$ in the following proof, furthermore we define:

$q=\frac{b-\bar{u}}{B}$

Basis:(28) holds true for $\mathrm{t}=1$ :

$$
\begin{aligned}
a_{1} & =q+(1-q) a_{0} \\
& =q \\
& =1-(1-q)^{1}
\end{aligned}
$$

Inductive step:

$$
\begin{aligned}
a_{k} & =1-(1-q)^{k} \Rightarrow a_{k+1}=1-(1-q)^{k+1} \\
a_{k+1} & =q+(1-q) a_{k} \\
& =q+(1-q)\left(1-(1-q)^{k}\right) \\
& =1+(1-q)^{k}(q-1) \\
& =1-(1-q)^{k+1}, \text { q.e.d. }
\end{aligned}
$$

We can now deduce the required $t_{1 \alpha}$ from the closedform expression:

$t_{1 \alpha}=\log _{1-\frac{b-\bar{u}}{B}}(1-\alpha)=\frac{\ln (1-\alpha)}{\ln \left(1-\frac{b-\bar{u}}{B}\right)}$

\section{Alternative 2: Supplementary tagging of returned containers}

In this case the company not only replenishes shrinkage with tagged containers, but additionally carries out supplementary tagging of returned containers. In each period those returned containers which are so far untagged are equipped with RFID tags during refurbishment. We assume that the fraction of tagged containers in $t$ is the same for the returned containers and the complete container inventory. In addition to the changes described for alternative 1 , the fraction of tagged containers increases by $\hat{\mathrm{u}}\left(1-\mathrm{a}_{2 \mathrm{t}}\right)$ per period. The recurrence relation for $\mathrm{a}_{2 \mathrm{t}}$ is:

$a_{2 t}= \begin{cases}0 & \text { if } t=0 \\ a_{2 t-1}+\frac{b\left(1-a_{2 t-1}\right)}{B} & \text { else }\end{cases}$

In this case the speed of diffusion is independent of the return rate. The closed-form expression of $a_{2 t}$ is given by:

$a_{2 t}=1-\left(1-\frac{b}{B}\right)^{t}$

This can be verified by inserting

$q=\frac{b}{B}$

for (29) in the proof of statement (28). Thus, the speed of diffusion of alternative 2 is:

$t_{2 \alpha}=\log _{1-\frac{b}{B}}(1-\alpha)=\frac{\ln (1-\alpha)}{\ln \left(1-\frac{b}{B}\right)}$

Evaluation of alternatives

Fig. 6 shows an exemplary development of the fraction of tagged containers over time after the first procurement of tagged containers:

We now determine the profitability of the alternatives. We assume that supplementary tagging is done until the necessary fraction $\alpha$ is reached. We further assume that the cost of equipping a returned container with a transponder equals the price difference between tagged and untagged containers $\left(\Delta \mathrm{k}_{\mathrm{p}}\right)$. It should be noted that this is a simplifying assumptions, as in reality the cost for supplementary tagging during refurbishment 
Fig. 6 Diffusion of RFID in the system

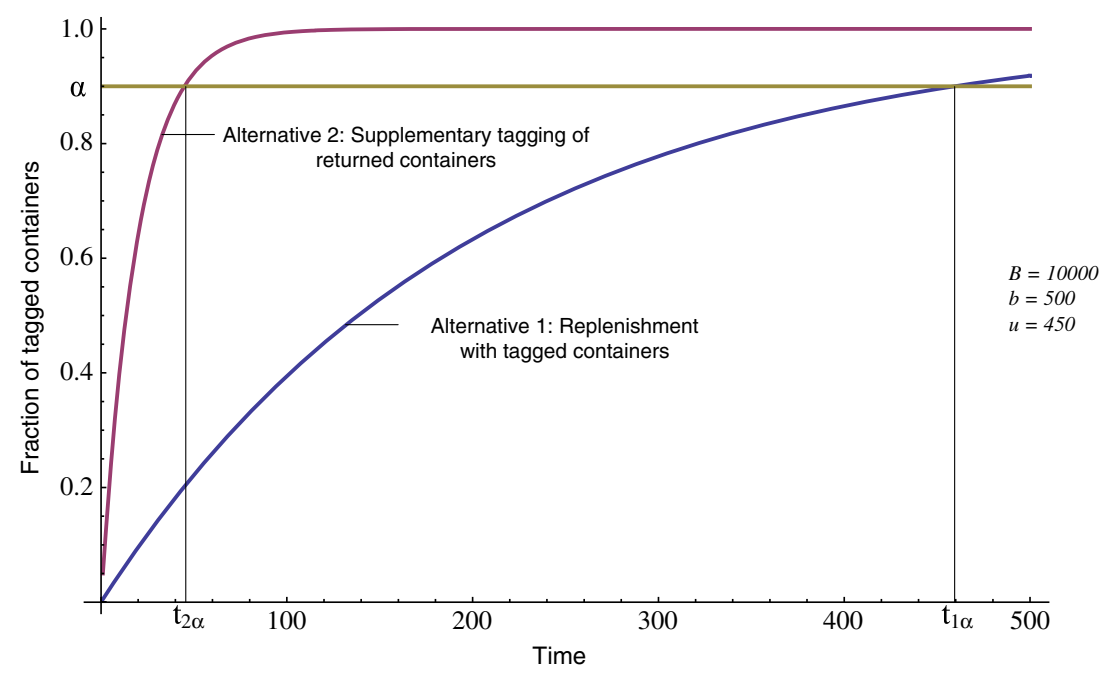

are probably higher in many cases. By applying alternative 2 , the following additional costs (relative to alternative 1) occur:

$$
\begin{aligned}
& \sum_{t=0}^{t_{2 \alpha}} \bar{u} \Delta k_{p}\left(1-a_{2 t}\right)=\bar{u} \Delta k_{p} \sum_{t=0}^{t_{2 \alpha}}\left(1-\frac{b}{B}\right)^{t} \\
& =\bar{u} \Delta k_{p} \frac{B}{b}\left(1-\left(1-\frac{b}{B}\right)^{t_{2 \alpha}+1}\right) \\
& =\bar{u} \Delta k_{p} \frac{B}{b}\left(1-\left(1-\frac{b}{B}\right)\left(\log _{1-\frac{b}{B}(1-\alpha)}\right)+1\right. \\
& =\bar{u} \Delta k_{p} \frac{B}{b}\left(1-(1-\alpha)\left(1-\frac{b}{B}\right)\right)
\end{aligned}
$$

On the other hand, there are benefits, as the increase of the return rate is reached earlier, if alternative 2 is applied:

$$
\begin{aligned}
\sum_{t=t_{2 \alpha} \alpha}^{t_{1 \alpha}}\left(C v_{R F I D}-C v_{0}\right)=\left(t_{1 \alpha}-t_{2 \alpha}+1\right) & \left(\left(b-u_{0}\right) \Delta k_{p}-\left(k_{p, 0}-k_{r}\right) \Delta u-\Delta k_{p} \Delta u\right) \\
= & \left(\log _{1-\frac{b-u}{B}}(1-\alpha)-\log _{1-\frac{b}{B}}(1-\alpha)+1\right) \\
& \left(\left(b-u_{0}\right) \Delta k_{p}-\left(k_{p, 0}-k_{r}\right) \Delta k_{p} \Delta u\right)
\end{aligned}
$$

Hence, supplementary tagging of returned containers is advantageous compared to exclusive replenishment with tagged containers, if

$$
\begin{aligned}
& -\left(\log _{1-\frac{b-\bar{u}}{B}}(1-\alpha)-\log _{1-\frac{b}{B}}(1-\alpha)+1\right) \\
& \quad\left(\left(b-u_{0}\right) \Delta k_{p}-\left(k_{p, 0}-k_{r}\right) \Delta u-\Delta k_{p} \Delta u\right) \\
& \quad>\bar{u} \Delta k_{p} \frac{B}{b}\left(1-(1-\alpha)\left(1-\frac{b}{B}\right)\right)
\end{aligned}
$$

The decision regarding implementation alternatives relies significantly on the ratio of the container demand rate (b) and the size of the complete container inventory in the system (B). If the complete container amount in the system is large relative to the container demand rate (possibly due to long cycle times for containers), supplementary tagging of returned containers is less favourable.

\section{Conclusion}

In this article we have analyzed the impact of RFID-based container tracking systems in a deterministic container inventory model. The analysis is based on a general reverse logistics model, which we have adapted, for our purpose. From case studies we have identified the main benefit of RFID-based container tracking systems to be an increase of container return rates, which we have modelled in our analysis. As costs of the RFID system, we focus on variable costs of tagging the containers. The implementation of the RFID system was then analyzed regarding changes to inventory policy, profitability and aspects of technology diffusion.

Changes to the optimum inventory control policy can be summarized as follows: Procurement of new containers is done less frequently and in smaller batches. The optimum refurbishment lot size decreases as well, but refurbishment is done more frequently. Subsequently we have determined the relationship of benefits and costs, necessary for a profitable use of the RFID system. Finally, implementation alternatives have been analyzed with respect to profitability. The size of the container inventory relative to the demand rate has been indentified as a significant determinant for the decision regarding implementation alternative.

This article provides one of the first insights into theoretical effects of the application of RFID in container management. Transferability of static and deterministic inventory models into reality is limited due to the inherent simplifying assumptions. Nonetheless, this article is relevant for research and practice: Companies interested in the potentials of RFID for container management may gain some insights into general effects and interdependencies of RFID-based container tracking, which have so far only been documented for isolated cases. Future research can use 
this work firstly as a starting point for the development of more complex, stochastic models in this important application area of RFID. Against the background of the growing importance of reverse logistics for research and practice, this work can secondly be of use for future analytical works dealing with RFID-based support of the reintegration of reverse material flows into supply chains.

Open Access This article is distributed under the terms of the Creative Commons Attribution Noncommercial License which permits any noncommercial use, distribution, and reproduction in any medium, provided the original author(s) and source are credited.

\section{References}

Aberdeen Group. (2004). 'RFID-Enabled Logistics Asset Management: Improving Capital Utilization, Increasing Availability, and Lowering Total Operational Costs', Boston.

Breen, L. (2006). Give me back my empties, or else! A preliminary analysis of customer compliance in reverse logistics practices (UK). Management Research News, 29(9), 532-551.

De Kok, A. G., van Donselaar, K. H., \& van Woensel, T. (2008). A break-even analysis of RFID technology for inventory sensitive to shrinkage. International Journal of Production Economics, $112(2), 521-531$.

Fleischmann, M., Bloemhof-Ruwaard, J., Dekker, R., van de Laan, E., van Nunen, J., \& Van Wassenhove, L. N. (1997). Quantitative models for reverse logistics: A review. European Journal of Operational Research, 103, 1-17.

Foster, P., Sindhu, A. \& Blundell, D. (2006). A Case Study to Track High Value Stillages using RFID for an Automobile OEM and its Supply Chain in the Manufacturing Industry', Proceedings of the 2006 IEEE International Conference on Industrial Informatics, pp. 56-60.

Harris, F. W. (1913). 'How Many Parts To Make At Once', Factory. The Magazine of Management, 10(2), 135-136.

Heese, H. S. (2007). Inventory Record Inaccuracy, Double Marginalization, and RFID Adoption. Production and Operations Management, 16(5), 542-553.

Hofmann, E., \& Bachmann, H. (2006) 'Behälter-Management in der Praxis: State-of-the-art und Entwicklungstendenzen bei der Steuerung von Ladungsträgerkreisläufen', Hamburg.

Johansson, O., \& Hellström, D. (2007). The effect of asset visibility on managing returnable transport items. International Journal of
Physical Distribution \& Logistics Management, 37(10), 799815.

Kang, Y., \& Gershwin, S. B. (2005). Information inaccuracy in inventory systems: stock loss and stockout. IIE Transactions, 37 (9), 843-859.

Kroon, L., \& Vrijens, G. (1995). Returnable containers: an example of reverse logistics. International Journal of Physical Distribution \& Logistics Management, 25(2), 56-68.

Lampe, M., \& Strassner, M. (2003). 'The Potential of RFID for Moveable Asset Management', Proceedings of the 5th International Conference on Ubiquitous Computing.

Lee, H., \& Özer, Ö. (2007). Unlocking the Value of RFID. Production and Operations Management, 16(1), 40-64.

LogicaCMG (2004) 'Making waves: RFID Adoption in Returnable Packaging', retrieved on 10 October 2008 from http://www. logicacmg.com/pdf/RFID.pdf

McKerrow, D. (1996). What makes reusable packaging systems work. Logistics Information Management, 9(4), 39-42.

Minner, S., \& Lindner, G. (2004). 'Lot Sizing Decisions in Product Recovery Management', In R. Dekker, M. Fleischmann, K. Inderfurth, L. N. Van Wassenhove (Eds.), Reverse Logistics: Quantitative Models for Closed-Loop Supply Chains (pp. 157179). Berlin Heidelberg.

Richter, K. (1996a). The EOQ repair and waste disposal model with variable setup numbers. European Journal of Operational Research, 95(2), 313-324.

Richter, K. (1996b). The extended EOQ repair and waste disposal model. International Journal of Production Economics, 45(1), 443-447.

Saygin, C. (2007). Adaptive inventory management using RFID data. The International Journal of Advanced Manufacturing Technology, 32(9), 1045-1051.

Schrady, D. A. (1967). A deterministic inventory model for repairable items. Naval Research Logistics Quarterly, 14(3), 391-398.

Sectoral e-Business Watch. (2008). 'RFID Adoption and Implications' Final Report, retrieved on 18 March 2009 from: http://www. ebusiness-watch.org/studies/special_topics/2007/documents/ Study_07-2008_RFID.pdf.

Strassner, M., \& Fleisch, E. (2005). Innovationspotenzial von RFID für das Supply-Chain-Management. Wirtschaftsinformatik, 47(1), $45-54$.

Teunter, R. H. (2001). Economic ordering quantities for recoverable item inventory systems. Naval Research Logistics, 48(6), 484495.

Vitzthum, S., \& Konsynski, B. (2008). CHEP: The Net of Things. Communications of the AIS, 22, 485-500.

Wilson, R. H. (1934). A Scientific Routine for Stock Control. Harvard Business Review, 13, 116-128.

Witt, C. E. (2000). Are Reusable Containers Worth the Cost? Transportation \& Distribution, 6(9), 105-108. 